\title{
THE ANALYSIS OF THE BASIC LAND MANAGER'S VOCABULARY NESTING MORPHEMES
}

\author{
Kateryna Yakushko \\ $\mathrm{PhD}$ in Pedagogy, Senior Lecturer, National University of Life \\ and Environmental Sciences of Ukraine, Ukraine \\ e-mail: vukladach@ukr.net, orcid.org/0000-0001-6977-8441
}

\section{Summary}

The relevance of the article is in introduction of the results of experimental linguistic studies concerning professional land manager's basic vocabulary morphemes nesting on practice. The purpose of the article is to describe the experiment of involving the statistic word-building nests analysis into communicative practice while studying professionally oriented English to improve soft foreign language communicative skills of future land managers. The conclusion of the study is that land manager's special vocabulary is characterized by some morphemes nesting to be selected by students themselves for the shortening of the term list for further dialogues within the positive linguistic studies experiment. The basic morphemes (without morpheme land-) include such representatives as adjust-, aer-, altitude-, area-, boni-, cadastr-, cartograph-, cost-, determination-, direction-, earth/Earth-, field-, fix-, geo-, grid-, lease-, level-, locat-, longitude-, map-, measure-, mone-, position-, photo-, relief-, soil-, survey-, terrain-, topograph-, work. The most spread types of land manager's vocabulary concerning basic morphemes are attribute-noun two components word combinations, noun-noun two components word combination and attribute-noun three-four component word combinations. Besides, the most spread basic morphemes within land manager's vocabulary are map-, geo-, soil-, measure- and direction-. The prospects of the research is the additional detailed characteristics of the morpheme land- as the most important for land manager's professional vocabulary morpheme for communicative purposes.

Keywords: linguistic experiment, word combination, land use specialist's terms, special features, basic word roots

DOI: https://doi.org/10.23856/3871

\section{Introduction}

Nowadays it is actual approach to regard nesting as one among other words creation ways for word combinations concluding either in general (Azarova, 2005) or concerning concrete morphemes being dealt with professional vocabulary (Yakushko, 2018). The area of adequate investigation may be exampled by vocabulary of land managers as the universal specialists dealing with actual modern activity concerning land law, land use, geodesy, land cadastre, land administration, engineering, economy, chemistry, agriculture, geography automation etc. for the adequate land-use planning surveying works taking into account ecological network state (Yakushko, 2019).

The purpose of the article is to describe the experiment of involving the statistic word-building nests analysis into communicative practice while studying professionally oriented English to improve soft foreign language communicative skills of future land managers. Linguistic studies concerning land manager's vocabulary morphemes were introduced on practice while English lessons for the bachelor's degree program students at the Faculty of Land Management being 
belonged to the National University of Life and Environmental Sciences of Ukraine in Kyiv. The experiment lasted during the second semester of 2019/2020 curriculum period.

Comparing with the specialized vocabulary in the sphere of automation the list of the land manager's specialized terms show that land manager's abbreviations (EDM, DWP, GPS, GIS etc.) are not strictly related to common word or to associative relations with emotional or psychomotor memories etc. (Yakushko, 2020). Thus, for the foreign language linguistic classes with future land managers we'd take into consideration only three items among the categories of professional vocabulary: 1) professional vocabulary being selected by common morpheme for adaptation to accept foreign terms by nesting method); 2) (professional vocabulary being selected by frequency of use in professional adapted texts); 3 ) (1 and 2 vocabulary within the shortened list of the most suitable for professional use term compounds (Yakushko, 2020).

\section{Basic land manager's vocabulary morphemes: structural features and relation to the part of speech in general description}

Now we'd like to represent the students' linguistic analyses of the main land management texts (Yakushko, 2019) morphemes to conclude statistical table for visuality aiming to distinguish the most common in use for the further shortening of vocabulary for professional communicative purposes taking into account that morpheme land-is the most nesting one for separate analysis in additional table (Yakushko, 2020).

The morphemes adjust-, aer-, altitude-, area-, boni-, cadastr-, cartograph-, cost-, determination-, direction-, earth/Earth-, field-, fix-, geo-, grid-, lease-, level-, locat-, longitude-, map-, measure-, mone-, position-, photo-, relief-, soil-, survey-, terrain-, topograph-, workwere represented by students in alphabetic order with the following descriptions:

Morpheme adjust- is in eight varieties: eight structures with of (adjusting of altimeter, adjusting of theodolite, adjusting of tacheometer, adjusting of tellurometer, adjusting of tripod, adjusting of bussol, adjusting of drone, adjusting of aerocamera).

Morpheme aer- is in eight varieties: one separate noun in one word (aerocamera), three attribute-noun two components word combinations (aerial scanner, aerial photography,aerial shooting), four attribute-noun three components word combinations (aerial scanner sampling, aerial visual observation, unmanned aerial vehicles), one noun-noun word combination (aerospace shooting).

Morpheme altitude- is in four varieties: one nesting item altitude, one noun-noun two components word combinations (point altitude), two noun-noun three components word combinations (point altitude mapping, relief section altitude).

Morpheme area- is in five varieties: one nesting item area, three attribute-noun two components word combinations (flat area, populated area, mountainous area), one noun -noun two components word combination (square area).

Morpheme boni- is in five varieties: two separate noun in one word (boning, bonitet), two noun-noun two components word combinations (soils boning, land bonitet), one nounnoun three components word combinations (land bonitet inventory).

Morpheme cadastre- is in seven varieties: one separate noun in one word (cadastre), one separate attribute in one word (cadastral), five attribute- noun two components word combinations (cadastral survey, cadastral map, cadastral inventory, cadastral cost, cadastral photoplan).

Morpheme cartograph- is in four varieties: one separate noun in one word (cartography), one separate attribute in one word (cartographic), two attribute- noun two components word combinations (cartographic projection, cartographic grid). 
Morpheme cost-is in four varieties: three noun-noun two components word combination (loan cost, mortgage cost, evaluation cost), one attribute-noun three components word combination (rental rate cost).

Morpheme determination- is in seven varieties: one nesting item determination, one noun-noun two components word combination (azimuth determination), two attribute-noun three components word combination (vertical angle determination, horizontal angle determination), three noun-noun three-four components word combinations (objects location determination, world sides determination, base line side determination).

Morpheme direction-is in thirteen varieties: one nesting item direction-, one separate attribute in one word (directional) four noun-noun three components word combinations (side direction definition, longitude direction indicator, altitude direction indicator, latitude direction indicator), seven attribute-noun two components word combintions (directional boring, directional angle, eastern direction, western direction, northern direction, southern direction, correct direction).

Morpheme earth/Earth- is in four varieties: one nesting item earth/Earth, three nounnoun two components word combinations (Earth surface, Earth Rotation, earth pattern), three multistructural word combination with of (three fundamental properties of the Earth, flat representations of the earth, problem, remote zoning of the Earth). Its specific feature is usage of two parallel variants (earth) and (Earth) for nesting in equal frequency.

Morpheme field- is in five varieties: one nesting item field, two noun-noun two components word combination (plants field, field maps), one noun-noun three components word combination (drone field experiments), one multistructural word combination with of (field of land manager's activity).

Morpheme fix- is in eight varieties: eight structures with of (fixing of altimeter, fixing of theodolite, fixing of tacheometer, fixing of tellurometer, fixing of tripod, fixing of bussol, fixing of drone, fixing of aerocamera).

Morpheme geo- is in thirty varieties: five separate one component nouns (geography, geoid, geodesy, geoinformatics, geo-informatics), two separate one component attributes (geodetic, geographical), eighteen attribute-noun two components word combinations (geographical grid, geographical coordinates, geodetic calculations, geodetic serif, geodetic network, geodetic mark, geodetic sign, geodetic coordinates, geodetic reference, geodetic works, geospatial information, geospatial data, geodetic survey, geodetic instruments, geospatial toolbox, geodetic measurements, geodetic grid; geodetic device), five attribute-noun three components word combinations (geodetic executive shooting, geodetic control network, multifunctional geodetic device, geodetic objects inventory, geographic information system).

Morpheme grid- is in four varieties: one nesting item grid-, two noun-noun two components word combinations (grid bearing, grid azimuth) and one attribute noun two components word combination (geodetic grid).

Morpheme lease- is in five varieties: one nest one component noun (lease), one nest one component attribute (leased), one noun-noun two components word combination (lease agreement), two attribute-noun two components word combinations (leased market, leased land).

Morpheme level-is in three varieties: one nest one component noun (level), two separate nouns in one word (leveling, leveler).

Morpheme locate- is in eleven varieties: two nest one component nouns (location, locality), one separate attribute (located), five attribute-noun two components word combination (located point, located pillar, urban locality, rural locality, separated locality), three noun-noun two components word combinations (settlements location, bearings location, objects location). 
Morpheme longitude- is in three varieties: one nest one component noun (longitude), two noun-noun two components word combinations (point longitude, longitude mapping).

Morpheme map- is in thirty eight varieties: one nest one component nouns (map), one separate noun in one word (mapping), twelve attribute-noun two components word combinations (mapping layout, cadastral maps, rolled maps, wall maps, pocket size maps, digital maps, field maps, cadastral map, folded maps, topographic maps, surveying maps, geographic maps), nine noun-noun two components word combinations (road maps, rainfall map, terrain map, map scale, map legend, rivers maps, atlas maps, map legend, primary mapping), ten noun-noun three components word combinations (soil erosion map, weather changes map, fertilization degree map, soil erosion maps, vegetation indices maps, fire location maps, solid lines maps, dotted lines maps, special purpose maps, ground works map, points series map, excavation works map), five attribute-noun three components word combinations (attributional data map, raw material maps, topographic shooting map three-dimensional representation maps, useful map properties, anthropogenic loading maps).

Morpheme measure- is in twenty varieties: sixteen noun-noun two components word combinations (angles measuring, superelevations measuring, hills measuring, trench measuring, slopes measuring, width measuring, measuring instruments, height measuring, theodolite measuring, depth measuring, distance measuring, land measuring, measurement error, measurement accuracy, autopilot measuring, measurements processing), four attribute-noun word combinationi (homogeneous points measurements, calibrated tube measurements, electronic distance measurement).

Morpheme mone- is in three varieties: one separate noun (moneylenders), one two components noun-noun word combination (money value), one multistructural word combination with of (monetary evaluation of land parcels).

Morpheme position is in six varieties: one nesting item position, three noun-noun two components word combinations (positioning layout, positioning drawing, objects positioning), one attribute-noun three components word combination (global positioning system), one nounnoun three components word combination (points position establishment).

Morpheme photo- is in five varieties: three noun-noun three components word combinations (terrain photo map, landscape photo map, digital photogramettic stations), two attribute-noun two components word combinations (relief map, digital photo).

Morpheme relief- is in three varieties: one nest one component noun (relief), one nounnoun two components word combination (relief shooting), one attribute-noun three components word combination (digital relief model).

Morpheme survey- is in seven varieties: one nest noun (survey), one separate noun in one word (surveyor), two separate attributes in one word (surveying, surveyed), three attribute-noun two components (surveying data, surveyed points, terrestrial surveying).

Morpheme soil- is in twenty three varieties: one nest one component noun (soil), one separate one word noun (topsoil), three adjective-noun two components word combinations (black soil, fertile soil, degradated soil, soggy soil, sandy soil), fourteen two components nounnoun word combination(soils boning, silt soil, sod soil, saline soil, rock soil, clay soil, soil samples, topsoil loss, soils temperature, soil conservation, soil protection, soil stabilization, soil types, soils fertilization, soil erosion ) and one adjective-noun three components combination (soil rational use).

Morpheme terrain- is in three varieties:one nest one component noun (terrain), one noun-noun two components word combination (terrain shooting), one attribute-noun three components word combination (digital terrain model). 
Morpheme topograph- is in four varieties: one separate noun in one word (topography), one separate attribute in one word (topographic), two attribute- noun two components word combinations (topographic map, topographic shooting).

Morpheme work- is in three varieties as three attribute-noun two components word combinations (working design, hydraulic works, geodetic work).

\section{Basic land manager's vocabulary nesting morphemes analysis result in an adequate table}

Abovenamed descriptions gave the basis to conclude adequate table 1 for visuality of the resulted calculations, meaning $A$ as total number of varieties, $B$ as nesting items, $C$ as separate noun in one word, $D$ as separate attribute in one word, $E$ as multistructural word combinations with of, $F$ as noun-noun two components word combination, $G$ as attribute- noun two components word combinations, $H$ as attribute- noun three-four component word combinations, $I$ as noun- noun three-four component word combinations.

Table 1

Basic land manager's vocabulary nesting morphemes analysis result

\begin{tabular}{|c|l|c|c|c|c|c|c|c|c|c|}
\hline & \multicolumn{1}{|c|}{} & \multicolumn{9}{|c|}{ The number (quantity of...) } \\
\hline $\mathbf{N}$ & \multicolumn{1}{|c}{ Morpheme } & $\mathbf{A}$ & $\mathbf{B}$ & $\mathbf{C}$ & $\mathbf{D}$ & $\mathbf{E}$ & $\mathbf{F}$ & $\mathbf{G}$ & $\mathbf{H}$ & I \\
\hline 1 & & 3 & 4 & 5 & 6 & 7 & 8 & 9 & 10 & 11 \\
\hline 1 & adjust- & $\mathbf{8}$ & 0 & 0 & 0 & 8 & 0 & 0 & 0 & 0 \\
\hline 2 & aer- & $\mathbf{8}$ & 0 & 1 & 0 & 0 & 1 & 3 & 3 & 0 \\
\hline 3 & altitude- & $\mathbf{4}$ & 1 & 0 & 0 & 0 & 1 & 0 & 2 & 0 \\
\hline 4 & area- & $\mathbf{5}$ & 1 & 0 & 0 & 0 & 1 & 3 & 0 & 0 \\
\hline 5 & boni- & $\mathbf{5}$ & 0 & 2 & 0 & 0 & 2 & 0 & 0 & 1 \\
\hline 6 & cadastr- & $\mathbf{7}$ & 0 & 1 & 1 & 0 & 0 & 5 & 0 & 0 \\
\hline 7 & cartograph- & $\mathbf{4}$ & 0 & 1 & 1 & 0 & 0 & 2 & 0 & 0 \\
\hline 8 & cost- & $\mathbf{4}$ & 0 & 0 & 0 & 0 & 3 & 0 & 1 & 0 \\
\hline 9 & determination- & $\mathbf{7}$ & 1 & 0 & 0 & 0 & 1 & 0 & 2 & 3 \\
\hline 10 & direction- & $\mathbf{1 3}$ & 1 & 0 & 1 & 0 & 0 & 7 & & 4 \\
\hline 11 & earth/Earth- & $\mathbf{7}$ & 1 & 0 & 0 & 3 & 3 & & & \\
\hline 12 & field- & $\mathbf{5}$ & 1 & 0 & 0 & 1 & 2 & 0 & 0 & 1 \\
\hline 13 & fix- & $\mathbf{8}$ & 0 & 0 & 0 & 8 & 0 & 0 & 0 & 0 \\
\hline 14 & geo- & $\mathbf{3 0}$ & 0 & 5 & 2 & 0 & 0 & 18 & 5 & 0 \\
\hline 15 & grid- & $\mathbf{4}$ & 1 & 0 & 0 & 0 & 2 & 1 & 0 & 0 \\
\hline 16 & lease- & $\mathbf{5}$ & 1 & 1 & 0 & 0 & 1 & 2 & 0 & 0 \\
\hline 17 & level- & $\mathbf{3}$ & 1 & 2 & 0 & 0 & 0 & 0 & 0 & 0 \\
\hline 18 & locat- & $\mathbf{1 1}$ & 0 & 2 & 1 & 0 & 3 & 5 & 0 & 0 \\
\hline 19 & longitude- & $\mathbf{3}$ & 1 & 0 & 0 & 0 & 2 & 0 & 0 & 0 \\
\hline 20 & map- & $\mathbf{3 8}$ & 1 & 1 & 0 & 0 & 9 & 12 & 5 & 10 \\
\hline 21 & measure- & $\mathbf{3}$ & 0 & 0 & 0 & 0 & 16 & 0 & 4 & 0 \\
\hline 22 & mone- & 0 & 1 & 0 & 1 & 1 & 0 & 0 & 0 \\
\hline 23 & position- & 0 & 0 & 0 & 0 & 0 & 0 & 2 & 3 \\
\hline 24 & photo- & $\mathbf{3}$ & 0 & 0 & 0 & 1 & 0 & 1 & 0 \\
\hline 25 & relief- & & & & & & & 0 \\
\hline
\end{tabular}


Table 1 (Continued)

\begin{tabular}{|c|l|c|c|c|c|c|c|c|c|c|}
\hline 1 & \multicolumn{1}{|c|}{2} & 3 & 4 & 5 & 6 & 7 & 8 & 9 & 10 & 11 \\
\hline 26 & soil - & $\mathbf{2 2}$ & 1 & 1 & 0 & 0 & 14 & 5 & 1 & 0 \\
\hline 27 & survey- & $\mathbf{7}$ & 1 & 1 & 2 & 0 & 0 & 3 & 0 & 0 \\
\hline 28 & terrain- & $\mathbf{3}$ & 1 & 0 & 0 & 0 & 1 & 0 & 1 & 0 \\
\hline 29 & topograph- & $\mathbf{4}$ & 0 & 1 & 1 & 0 & 0 & 2 & 0 & 0 \\
\hline 30 & work- & $\mathbf{3}$ & 0 & 0 & 0 & 0 & 0 & 3 & 0 & 0 \\
\hline & Total amount & $\mathbf{2 6 1}$ & $\mathbf{1 6}$ & $\mathbf{2 0}$ & $\mathbf{9}$ & $\mathbf{2 1}$ & $\mathbf{6 4}$ & $\mathbf{7 1}$ & $\mathbf{3 8}$ & $\mathbf{2 2}$ \\
\hline
\end{tabular}

Thus, from the two hundred sixty one varieties there are sixteen nesting items, twenty separate nouns in one word, nine separate attributes in one word, twenty one multistructural word combinations with of, sixty four noun-noun two components word combinations, seventy one attribute-noun two components word combinations, thirty eight attribute- noun three-four component word combinations and twenty two noun- noun three-four component word combinations.

\section{The clichés of land manager's dialogue with the shortened list of morphemes.}

The most spread of the analyzed morphemes may pay attention to the shortening of the wide list of land manager's morphemes basing upon map-, geo-, soil-, measure- and directionas the most frequent in English professional texts.

They may be involved into the further students' dialogues basing upon the following dialogue clichés in table 2:

Table 2

The clichés of land manager's dialogue with the shortened list of morphemes

\begin{tabular}{|c|c|c|}
\hline $\mathbf{N}$ & The first student 's replica cliché & The second student 's replica cliché \\
\hline 1 & - Hello, future land manager. Nice to meet you. & - Hi, nice to meet you too. Can I help you? \\
\hline 2 & $\begin{array}{l}\text { - Yes, you can. Let us discuss the most com- } \\
\text { mon word combinations for land manager's } \\
\text { conversation. }\end{array}$ & -What are they? \\
\hline 3 & $\begin{array}{l}\text { - From our previous analysis they are based } \\
\text { on the such morphemes as map-, geo-, soil-, } \\
\text { measure - and direction-. }\end{array}$ & $\begin{array}{l}\text { - Let us conclude real land manager's life } \\
\text { story(tale) concerning these morphemes. }\end{array}$ \\
\hline 4 & - I agree. Once upon a time.... & $\begin{array}{l}\text { - What were the adequate basic land man- } \\
\text { ager's vocabulary morphemes? }\end{array}$ \\
\hline 5 & - They were... & $\begin{array}{l}\text { - What concepts or processes do these } \\
\text { word combinations mean? }\end{array}$ \\
\hline 6 & $\begin{array}{l}\text { - Well, such word combination with mor- } \\
\text { pheme map- as.... mean..., such word com- } \\
\text { bination with morpheme geo- as.... mean... } \\
\text { and such word combination with morpheme } \\
\text { soil-, mean ... Besides, such word combina- } \\
\text { tion with morpheme measure - as... mean... } \\
\text { and such word combination with morpheme } \\
\text { direction- as... mean... }\end{array}$ & $\begin{array}{l}\text { - Thank for your answers. Let's continue } \\
\text { linguistic studies on our next English } \\
\text { classes. }\end{array}$ \\
\hline 7 & - Not at all. See you later. Bye. & - Bye. \\
\hline
\end{tabular}


The students were satisfied with the linguistic studies. We consider the experiment of involving the statistic word-building nests analysis into communicative practice while studying professionally oriented English to be positive.

\section{Conclusions}

The conclusion of the study is that land manager's special vocabulary is characterized by some morphemes nesting to be selected by students themselves for the shortening of the term list for further dialogues within the positive linguistic studies experiment. The basic morphemes (without morpheme land-) include such representatives as adjust-, aer-, altitude-, area-, boni-, cadastr-, cartograph-, cost-, determination-, direction-, earth/Earth-, field-, fix-, geo-, grid-, lease-, level-, locat-, longitude-, map-, measure-, mone-, position-, photo-, relief-, soil-, survey-, terrain-, topograph-, work-. The most spread types of land manager's vocabulary concerning basic morphemes are attribute-noun two components word combinations, noun-noun two components word combination and attribute- noun three-four component word combinations. Besides, the most spread basic morphemes within land manager's vocabulary are map-, geo-, soil-, measure- and direction-. The prospects of the research is the additional detailed characteristics of the morpheme land- as the most important for land manager's professional vocabulary morpheme for communicative purposes.

\section{References}

Azarova, L. Y., Piast, H. Y. (2005). Skladannia yak odyn iz sposobiv slovotvoru [Nesting as one among other words creation ways]. Vinnytsia: UNIVERSUM [in Ukrainian].

Yakushko, K. H. (2019). Anglijska mova dlia pidhotovky fakhivtsiv OS “Bakhalavr” zi spetsialnosti "Geodeziya ta zemleustrij”" [English for Geodesy]. Kyiv: Eאspo-Druk [in Ukrainian].

Yakushko, K. H. (2020). Anglomovni vidpovidnyky osnovnykh moorfem terminiv zemlevporiadkuvannia / Tavrijki fililihichni naukovi chytannia: materialy mizhnarodnoji naukovo-praktychnoji konferentsiji 24-25 sichnia $2020 \mathrm{r}$ Ch.2. [English equivalents to the land management basic morphemes/Tavrida philological meetings: materials of the international January 24-25 2020 scientific conference P. 2]. Kyiv: Helvetyka [in Ukrainian].

Yakushko, K. H. (2020). The categories of specialized vocabulary in the sphere of automation to develop students' foreign language communicative skills/Modern researches in philological sciences: collective monograph. Romania: Baia Mare. 2020.

Yakushko, K. H. (2018). Osoblyvosti leksychnoho skladu ta chastotnosti vzhyvannia aanhliiskykh terminolohichnykh spoluk z morfemoyu aut-/ Molodyi vchenyi № 7(59) [Lexic structure and frequency usage features of English terminological compounds with morpheme aut]. Kherson: Molodyi vchenyi [in Ukrainian]. 